\title{
OPTIMALISASI DISTRIBUSI RUANG TERBUKA HIJAU (RTH) DI KELURAHAN BANTA-BANTAENG KECAMATAN RAPPOCINI KOTA MAKASSAR
}

\author{
Nashrah Arsyad \\ Prodi Arsitektur, Fakultas Teknik, Universitas Muslim Indonesia
}

\begin{abstract}
Abstrak
Luas Ruang Terbuka Hijau (RTH) suatu wilayah yang ideal adalah minimal 30\% dari luas kawasan perkotaan. Namun dalam kenyataannya ketersediaan Ruang Terbuka Hijau dihampir semua kota di Indonesia rata-rata baru mencapai $10 \%$ dari luas wilayah. Ketersediaan Ruang terbuka Hijau yang terbatas dan sebaran yang tidak merata serta terkonsentrasinya ruang terbuka hijau pada titik-titik tertentu di beberapa wilayah mengakibatkan pertumbuhan dan perkembangan kota menjadi timpang dan cenderung semrawut. Penelitian ini bertujuan untuk mengidentifikasi ketersediaan Ruang Terbuka Hijau dan untuk menganalisis optimalisasi distribusi Ruang Terbuka hijau menurut jenis dan fungsinya di Kota Makassar. Penelitian ini dilaksanakan di Kota Makassar dengan mengambil lokasi studi pada Kelurahan Banta-bantaeng Kecamatan Rappocini Kota Makassar, dengan waktu penelitian mulai dari bulan Juli 2016 sampai dengan bulan April 2017. Metode yang digunakan dalam penelitian ini metode deskriptif kualitatif dan deskriptif kuantitatif. Metode deskriptif kualitatif digunakan untuk mengidentifikasi ketersediaan jenis dan fungsi Ruang Terbuka Hijau sedangkan metode deskriptif kuantitatif digunakan untuk menggambarkan kebutuhan dan distribusi ruang terbuka hijau di Kota Makassar melalui perhitungan rumus matematis sederhana dan proyeksi jumlah penduduk. Hasil penelitian ini menunjukkan bahwa ketersediaan ruang terbuka Hijau di Kota Makassar khususnya di Kelurahan Bantabantaeng belum memenuhi standard kebutuhan ruang terbuka Hijau ditinjau dari luas wilayah dan jumlah penduduk. Hasil penelitian ini juga menunjukkan bahwa penyebaran ruang terbuka belum terdistribusi secara optimal diantaranya karena terbatasnya ruang kosong di beberapa wilayah Kelurahan Banta-bantaeng yang disebabkan oleh padatnya permukiman penduduk
\end{abstract}

Kata kunci: distribusi, optimalisasi, Ruang Terbuka Hijau

\section{PENDAHUUAN}

Ruang Terbuka Hijau adalah salah satu elemen kota yang sangat penting dalam keberlanjutan kualitas suatu kota. Menurut Shirvani (1985), Ruang terbuka haruslah dianggap sebagai bagian integral dari suatu perencanaan kota. Meskipun demikian, ketersediaan dan pemenuhan kebutuhan ruang terbuka hijau dihampir semua kota di Indonesia belum juga mencukupi. Penyediaan RTH di Kawasan Perkotaan dibagi atas 3 bagian meliputi penyediaan berdasarkan luas wilayah, penyediaan berdasarkan jumlah penduduk, dan penyediaan berdasarkan kebutuhan fungsi tertentu.

Berdasarkan Undang-undang No. 26 tahun 2007 tentang Penataan Ruang, menetapkan bahwa setiap wilayah kota harus menyediakan Ruang Terbuka Hijau sebesar $30 \%$ dari luas wilayah yang terdiri atas $20 \%$ RTH publik dan 10\% RTH privat. Proporsi luasan ruang terbuka hijau kota tersebut merupakan ukuran minimal untuk menjamin keseimbangan ekosistem kota baik keseimbangan sistem hidrologi dan keseimbangan mikroklimat, maupun sistem ekologis lain yang dapat meningkatkan ketersediaan udara bersih yang diperlukan masyarakat, ruang terbuka bagi aktivitas publik serta sekaligus dapat meningkatkan nilai estetika kota (Hakim,2004). Pada kenyataannya, Ruang Terbuka Hijau yang tersedia pada sebagian besar kota di Indonesia termasuk Makassar rata-rata hanya sebesar 6\%-8\%.
Kurangnya ketersediaan Ruang Terbuka Hijau dikota Makassar diperkuat oleh Samsuddin Amin (2011) dalam penelitiannya tentang evaluasi ketersediaan Ruang Terbuka Hijau di Kompleks Perumahan Bumi Permata Sudiang yang menyatakan bahwa ketersediaan Ruang Terbuka Hijau pada lokasi penelitiannya belum memenuhi persyaratan Dengan luas lahan sebesar 54.907,10 m2, maka prosentase jumlah/luasan Ruang Terbuka Hijau di lokasi penelitian adalah sebesar 21,10\% dengan rincian Ruang Terbuka Hijau Publik sebesar 12,61\% dan Ruang Terbuka Hijau Privat sebesar $8,49 \%$.

Ketersediaan Ruang terbuka Hijau yang terbatas serta terkonsentrasinya ruang terbuka hijau pada titik-titik tertentu di beberapa wilayah mengakibatkan pertumbuhan dan perkembangan kota menjadi timpang dan cenderung semrawut.

Dengan demikian terlihat bahwa perlu dilakukan suatu penelitian tentang optimalisasi distribusi Ruang Terbuka Hijau di Kota Makassar. Penelitian ini dilakukan bukan hannya untuk mengetahui kebutuhan Ruang Terbuka Hijau di Kota Makassar menurut jenis dan fungsinya tetapi juga akan mengkaji optimalisasi distribusi RTH sehingga distribusi RTH pada wilayah-wilayah kecamatan hingga kelurahan dapat diketahui berdasarkan kebutuhan masyarakat terhadap RTH. 


\section{ISI PENELITIAN}

\subsection{Metode}

Jenis penelitian yang digunakan adalah penelitian deskriptif dengan pendekatan kualitatif. Jenis data terbagi menjadi dua yaitu data primer dan sekunder. Data primer diperoleh secara langsung dengan melakukan observasi di lapangan serta wawancara langsung yang berhubungan dengan data-data yang dibutuhkan berupa data tentang banjir, guna lahan dan lain sebagainya. Data Sekunder, diperoleh dari kantor instansi terkait (dokumentasi) yang mengetahui fisik lingkungan berupa topografi kawasan, serta referensi-referensi lainya yang relevan dengan masalah pokok dalam penelitian ini.

\subsection{Hasil dan Pembahasan}

2.2.1 Gambaran Umum Kelurahan Banta-bantaeng Kecamatan Rappocini Makassar

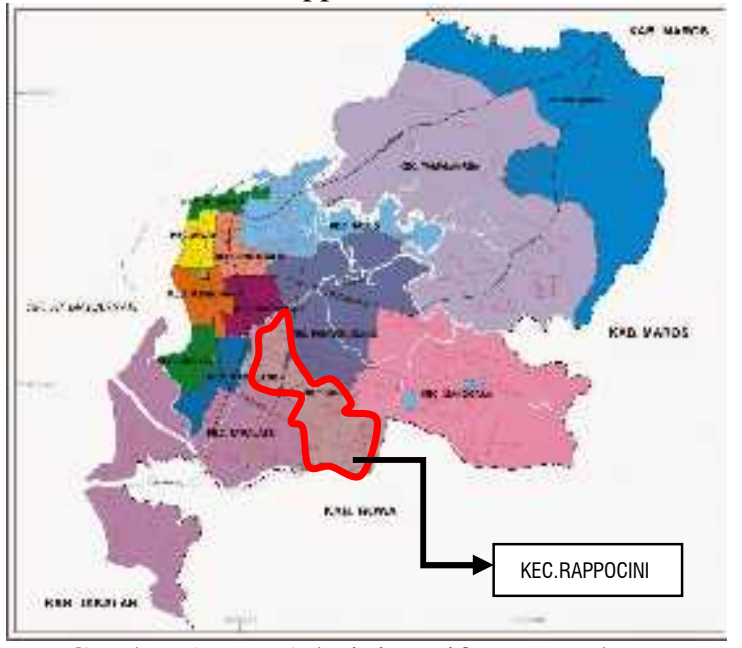

Gambar.1 Peta Administratif Kota Makassar Sumber : www.makassar.go.id

Adapun batas - batas kelurahan Rappocini sebagai berikut :

a. Disebelah Utara berbatasan dengan Kelurahan Rappocini dan Kelurahan Buakana di Jl.Rappocini raya,

b. Disebalah Timur berbatasan dengan Kelurahan Tidung di Jl. A. Pettarani,

c. Disebalah Barat berbatasan dengan Kelurahan Mamajang Dalam di Jl. Veteran Selatan,

d. Disebelah Selatan berbatasan dengan Kelurahan Pa'baeng- Baeng di Jl. Sultan Alauddin.

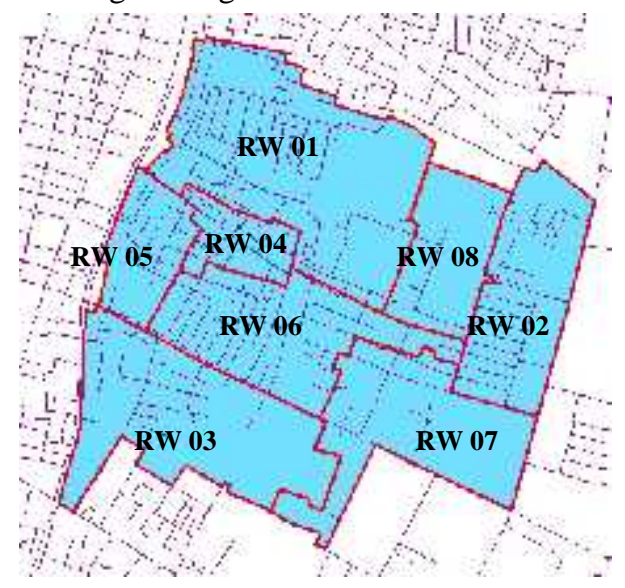

Gambar.2 Peta Administratif Kota Makassar Sumber : digitasi google.earth

Kelurahan Banta - Bantaeng adalah salah satu kelurahan di Kecamatan Rappocini Kota Makassar yang memiliki luas wilayah $1.462 .031 .177 \mathrm{Ha}$ atau $1.46 \mathrm{~km}^{2}$.

\subsubsection{Kondisi Administratif}

Kelurahan Banta - Bantaeng terdiri dari 8 RW dan 70 RT. Berdasarkan luas wilayah RW 01 termasuk yang paling luas dan RW 04 memiliki luas wilayah paling kecil.

Tabel 1. Luas Wilayah Kelurahan Banta-bantaeng berdasarkan RW

\begin{tabular}{|c|c|}
\hline RW & Luas Wilayah $\left(\mathbf{M}^{\mathbf{2}}\right)$ \\
\hline RW 01 & 604.432 \\
\hline RW 02 & 210.052 \\
\hline RW 03 & 372.536 \\
\hline RW 04 & 93.718 \\
\hline RW 05 & 121.397 \\
\hline RW 06 & 212.903 \\
\hline RW 07 & 205.754 \\
\hline RW 08 & 183.747 \\
\hline
\end{tabular}

Sumber : Data Kelurahan 2017

\subsubsection{Ketersediaan Ruang Terbuka Hijau}

Ruang Terbuka Hijau yang tersedia berdasarkan luas wilayah adalah sebesar $30 \%$ dari luas wilayah yang terbagi atas 20\% RTH publik dan $10 \%$ RTH privat. Untuk Keluarahan Banta-bantaeng, ketersediaan RTH publik berdasarkan standar luas wilayah dapat dilihat pada tabel di bawah ini.

Tabel 2. Luas RTH berdasarkan Luas Wilayah tiap RW Kelurahan Banta-bantaeng

\begin{tabular}{|c|c|c|c|}
\hline RW & $\begin{array}{c}\text { Luas } \\
\text { Wilayah } \\
\left.\mathbf{( M}^{\mathbf{2}}\right)\end{array}$ & $\begin{array}{c}\text { Ratio } \\
\text { Luas } \\
\text { RTH }\end{array}$ & $\begin{array}{c}\text { Luas RTH } \\
(\mathbf{m} 2)\end{array}$ \\
\hline RW 01 & 604.432 & & $120.886,40$ \\
\hline RW 02 & 210.052 & & $42.010,40$ \\
\hline RW 03 & 372.536 & & $74.507,20$ \\
\hline RW 04 & 93.718 & \multirow{4}{*}{$20 \%$} & $18.743,60$ \\
\hline RW 05 & 121.397 & & $24.279,40$ \\
\hline RW 06 & 212.903 & & $42.580,60$ \\
\hline RW 07 & 205.754 & & $41.150,80$ \\
\hline RW 08 & 183.747 & & 36749,40 \\
\hline
\end{tabular}

Sumber : Hasil Olah Data dari Kelurahan

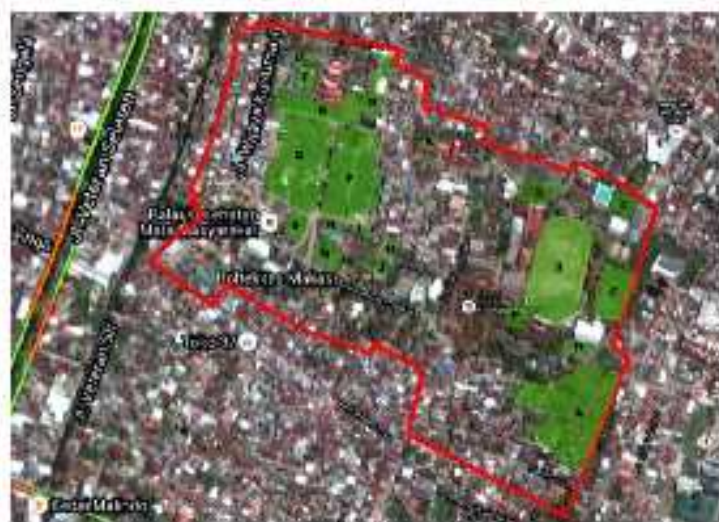


Gambar.3 Peta ketersediaan dan penyebaran ruang terbuka hijau RW 01 Kelurahan Banta-bantaeng tahun 2017

Sumber : Google Earth

\section{a. RW 01}

Berdasarkan hasil data survey dan pengamatan, menunjukkan bahwa di RW 01 tidak terdapat RTH berupa taman kompleks melainkan hanya terdapat beberapa lahan kosong milik masyarakat atau instansi dan sebuah lapangan olah raga private milik sebuah kampus yang dijadikan lahan untuk berolahraga oleh masyarakat.

Tabel 3. Ketersediaan Ruang Terbuka Di RW 01 Kelurahan Banta-bantaeng

\begin{tabular}{|c|c|c|c|}
\hline Notasi & $\begin{array}{c}\text { Luas } \\
\left(\mathbf{m}^{2}\right)\end{array}$ & $\begin{array}{c}\text { Hak } \\
\text { Kepemilikan } \\
\end{array}$ & Keterangan \\
\hline A & 18.118 & Kodam & $\begin{array}{l}\text { Sebagian di } \\
\text { tanami } \\
\text { pepohonan } \\
\text { pisang, } \\
\text { sebagian lagi } \\
\text { di tumbuhi } \\
\text { rumput liar }\end{array}$ \\
\hline B & 154.199 & UNM & $\begin{array}{c}\text { Lap. Sepak } \\
\text { bola, kondisi } \\
\text { baik, terawat }\end{array}$ \\
\hline $\mathrm{C}$ & 5.023 & UNM & $\begin{array}{c}\text { Lahan hijau, } \\
\text { biasa } \\
\text { digunakan } \\
\text { sepak bola, } \\
\text { agak terawat }\end{array}$ \\
\hline $\mathrm{D}$ & 1.106 & UNM & $\begin{array}{l}\text { Lahan } \\
\text { kosong. } \\
\text { Ditumbuhi } \\
\text { rumput liar, } \\
\text { tidak terawat }\end{array}$ \\
\hline $\mathrm{E}$ & 1.479 & POLTEKES & $\begin{array}{c}\text { Lahan } \\
\text { kosong, tidak } \\
\text { terawat }\end{array}$ \\
\hline $\mathrm{F}$ & 1.412 & UNM & \\
\hline G & 2.308 & UNM & $\begin{array}{l}\text { Lahan untuk } \\
\text { parkiran }\end{array}$ \\
\hline $\mathrm{H}$ & 600 & Pemerintah & $\begin{array}{c}\text { Kurang } \\
\text { terawat, } \\
\text { berada di } \\
\text { pinggir jalan }\end{array}$ \\
\hline I & 807 & Pengembang & $\begin{array}{c}\text { Lahan } \\
\text { kosong } \\
\text { ditumbuhi } \\
\text { rumput liar }\end{array}$ \\
\hline $\mathrm{J}$ & 805 & Pribadi & $\begin{array}{c}\text { Lahan } \\
\text { kosong } \\
\text { ditumbuhi } \\
\text { rumput liar }\end{array}$ \\
\hline $\mathrm{K}$ & 451 & Pribadi & $\begin{array}{l}\text { Di tumbuhi } \\
\text { rumput liar, } \\
\text { tidak terawat }\end{array}$ \\
\hline
\end{tabular}

\begin{tabular}{|c|c|c|c|}
\hline $\mathrm{L}$ & 520 & Pribadi & $\begin{array}{c}\text { Lahan } \\
\text { kosong } \\
\text { ditumbuhi } \\
\text { rumput liar }\end{array}$ \\
\hline M & 1.756 & Pengembang & $\begin{array}{c}\text { Lahan } \\
\text { kosong } \\
\text { ditumbuhi } \\
\text { rumput liar }\end{array}$ \\
\hline $\mathrm{N}$ & 696 & Pengembang & $\begin{array}{c}\text { Lahan } \\
\text { kosong } \\
\text { ditumbuhi } \\
\text { rumput liar }\end{array}$ \\
\hline $\mathrm{O}$ & 1.506 & Pengembang & $\begin{array}{c}\text { Lahan } \\
\text { kosong } \\
\text { ditumbuhi } \\
\text { rumput liar }\end{array}$ \\
\hline $\mathrm{P}$ & 11.432 & Pengembang & $\begin{array}{c}\text { Lahan } \\
\text { kosong } \\
\text { ditumbuhi } \\
\text { rumput liar }\end{array}$ \\
\hline Q & 13.814 & Pengembang & $\begin{array}{c}\text { Lahan } \\
\text { kosong } \\
\text { ditumbuhi } \\
\text { rumput liar }\end{array}$ \\
\hline $\mathrm{R}$ & 3.595 & Pengembang & $\begin{array}{c}\text { Lahan } \\
\text { kosong } \\
\text { ditumbuhi } \\
\text { rumput liar }\end{array}$ \\
\hline$S$ & 3.209 & $\begin{array}{c}\text { Kampus } \\
\text { Akper Angin } \\
\text { Mamiri }\end{array}$ & $\begin{array}{c}\text { Lahan } \\
\text { kosong, } \\
\text { kondisi tidak } \\
\text { begitu } \\
\text { terawat }\end{array}$ \\
\hline $\mathrm{T}$ & 1.196 & $\begin{array}{c}\text { Kampus } \\
\text { Akper Angin } \\
\text { Mamiri }\end{array}$ & $\begin{array}{l}\text { Berupa } \\
\text { taman, } \\
\text { kondisi } \\
\text { terawat }\end{array}$ \\
\hline $\mathrm{U}$ & 744 & $\begin{array}{c}\text { Kampus } \\
\text { Akper Angin } \\
\text { Mamiri }\end{array}$ & $\begin{array}{l}\text { Berupa } \\
\text { taman, } \\
\text { kondisi } \\
\text { terawat }\end{array}$ \\
\hline TOTAL & \multicolumn{2}{|c|}{224.776} & \\
\hline
\end{tabular}

Sumber : Data Primer

b. RW. 02

Ketersediaan RTH pada RW 02 lebih sedikit, yaitu hanya terdapat sebuah lahan kosong yang dijadikan lapangan voli serta beberapa taman kompleks tak terawat dan beberapa rumah masyarakat yang tersedia hanya sedikit saja kalau ada, bahkan terdapat beberapa rumah yang tidak memiliki ruang terbuka hijau.

Tabel 4. Ketersediaan Ruang Terbuka Di RW 02

\begin{tabular}{|c|c|c|c|}
\hline Notasi & $\begin{array}{c}\text { Luas } \\
\left(\mathbf{m}^{\mathbf{2}}\right)\end{array}$ & $\begin{array}{c}\text { Hak } \\
\text { Kepemilikan }\end{array}$ & Keterangan \\
\hline A & 2.770 & Pemerintah & $\begin{array}{c}\text { Lahan kosong } \\
\text { yang tidak } \\
\text { terawat }\end{array}$ \\
\hline B & 1.011 & $\begin{array}{c}\text { Balai Diklat } \\
\text { BPI }\end{array}$ & $\begin{array}{c}\text { Lahan kosong, } \\
\text { agak sedikt }\end{array}$ \\
\hline
\end{tabular}


Jurnal Arsitektur, Kota dan Permukiman (LOSARI)

\begin{tabular}{|c|c|c|c|}
\hline C & 1.958 & $\begin{array}{c}\text { Balai Diklat } \\
\text { BPI }\end{array}$ & $\begin{array}{c}\text { Lahan kosong, } \\
\text { agak sedikt } \\
\text { terawat }\end{array}$ \\
\hline D & 1.618 & $\begin{array}{c}\text { Balai Diklat } \\
\text { BPI }\end{array}$ & $\begin{array}{c}\text { Lahan kosong, } \\
\text { ditumbuhi } \\
\text { rumput liar, } \\
\text { tidak terawat }\end{array}$ \\
\hline E & 778 & Pribadi & $\begin{array}{c}\text { Lap. Bulu } \\
\text { tangkis, kurang } \\
\text { terawat, }\end{array}$ \\
\hline F & 1.429 & $\begin{array}{c}\text { Taman } \\
\text { Kompleks }\end{array}$ & $\begin{array}{c}\text { komplek, tidak } \\
\text { terawat }\end{array}$ \\
\hline G & 1.030 & Pribadi & $\begin{array}{c}\text { Lahan terbuka, } \\
\text { biasa di } \\
\text { gunakan untuk } \\
\text { berolahrag bulu } \\
\text { tangkis }\end{array}$ \\
\hline TOTAL & & \multicolumn{1}{|c|}{10.594} & \\
\hline
\end{tabular}

Sumber : Data Primer

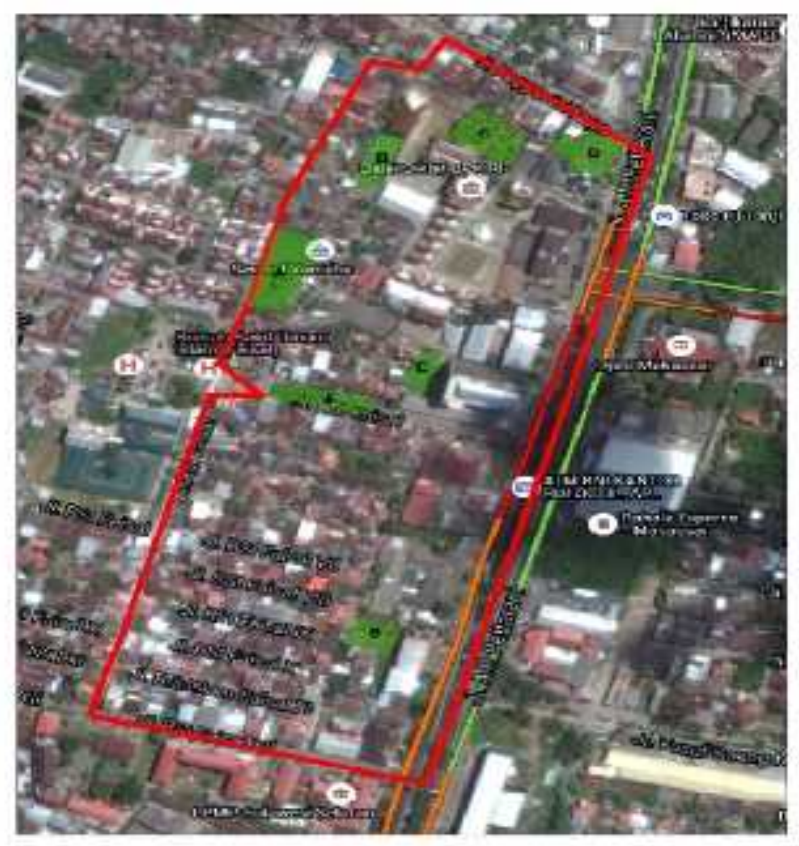

Gambar. 4 Peta Ketersediaan dan penyebaran ruang Terbuka RW 01 Kelurahan Banta-bantaeng Sumber : Google Earth

c. RW. 03

Tabel 5. Ketersediaan Ruang Terbuka pada RW. 03 Kelurahan Banta- bantaeng Sumber : Data primer 2017

\begin{tabular}{|c|c|c|c|c|}
\hline Notasi & $\begin{array}{c}\text { Luas / } \\
\mathbf{m}^{\mathbf{2}}\end{array}$ & Status & Kondisi & Aktivitas \\
\hline $\mathbf{A}$ & 3.464 .25 & $\begin{array}{c}\text { Milik } \\
\text { Pribadi }\end{array}$ & $\begin{array}{c}\text { Tiidak } \\
\text { Terawat }\end{array}$ & $\begin{array}{c}\text { Tidak } \\
\text { Ada }\end{array}$ \\
\hline $\mathbf{B}$ & $8.631,33$ & $\begin{array}{c}\text { Milik } \\
\text { Pribadi }\end{array}$ & $\begin{array}{c}\text { Tiidak } \\
\text { Terawat }\end{array}$ & $\begin{array}{c}\text { Tidak } \\
\text { Ada }\end{array}$ \\
\hline $\mathbf{C}$ & $7.324,81$ & $\begin{array}{c}\text { Milik } \\
\text { Pribadi }\end{array}$ & $\begin{array}{c}\text { Tiidak } \\
\text { Terawat }\end{array}$ & $\begin{array}{c}\text { Tidak } \\
\text { Ada }\end{array}$ \\
\hline
\end{tabular}

\begin{tabular}{|c|c|c|c|c|}
\hline D & $2.973,02$ & $\begin{array}{c}\text { Milik } \\
\text { Pribadi }\end{array}$ & $\begin{array}{c}\text { Tiidak } \\
\text { Terawat }\end{array}$ & $\begin{array}{c}\text { Tidak } \\
\text { Ada }\end{array}$ \\
\hline $\mathbf{E}$ & $\begin{array}{c}160,96 \\
\mathrm{~m}^{2}\end{array}$ & $\begin{array}{c}\text { Milik } \\
\text { Pribadi }\end{array}$ & $\begin{array}{c}\text { Tiidak } \\
\text { Terawat }\end{array}$ & $\begin{array}{c}\text { Tidak } \\
\text { Ada }\end{array}$ \\
\hline $\mathbf{F}$ & $\begin{array}{c}116,84 \\
\mathrm{~m}^{2}\end{array}$ & $\begin{array}{c}\text { Milik } \\
\text { Pribadi }\end{array}$ & $\begin{array}{c}\text { Tiidak } \\
\text { Terawat }\end{array}$ & $\begin{array}{c}\text { Tidak } \\
\text { Ada }\end{array}$ \\
\hline $\mathbf{G}$ & $\begin{array}{c}165,83 \\
\mathrm{~m}^{2}\end{array}$ & $\begin{array}{c}\text { Milik } \\
\text { Pribadi }\end{array}$ & $\begin{array}{c}\text { Tiidak } \\
\text { Terawat }\end{array}$ & $\begin{array}{c}\text { Tidak } \\
\text { Ada }\end{array}$ \\
\hline Jumlah & \multicolumn{2}{|c|}{$22.837,04 \mathrm{~m}^{2}$} & & \\
\hline
\end{tabular}

Sumber : Data primer 2017

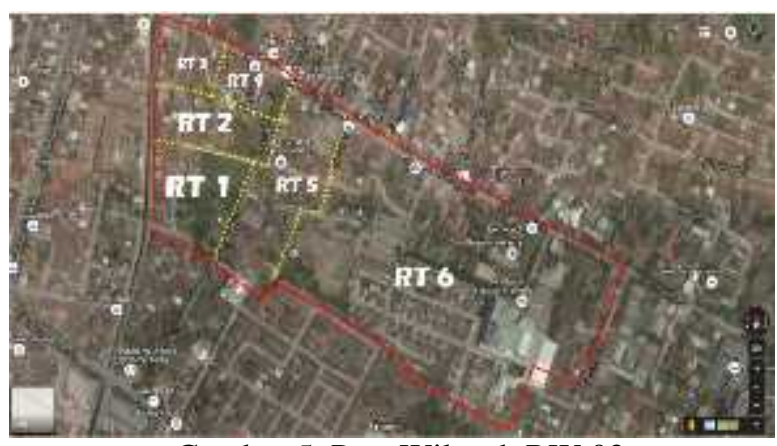

Gambar 5. Peta Wilayah RW.03

Keluarahan Banta-bantaeng

Sumber : Google Earth 2017

Kebutuhan RTH RW 3

a. Berdasarkan jumlah penduduk $2540=30 \% \times 212.903=63,87 \mathrm{~m}^{2}$

b. Berdasarkan Luas Wilayah (populasi) $20 \% \times 2540=508 \mathrm{~m}^{2}$

\section{d.RW. 04}

Pada RW. 04 berdasarkan data survey diketahui diketahui bahwa RTHyang tersedia sangat minim bahkan boleh dikata tidak ada. RW004 merupakan daerah yang padat dan bangunannya sangat berdempet-dempetan. Adapun RTH yang tersedia pada RW 04 terdapat pada RT. 10 dimana RT.10 itu merupakan perumahan Ayu Lestari dan didalam perumahan tersebut terdapat RTH. RTH yang ada pada perumahan tersebut merupakan taman-taman yang prosentasinya sangat kecil. Taman yang ada pada perumahan ini hanya sebuah taman yang berfungsi sebagai elemen estetis ekologis daerah tersebut dan tidak bisa melakukan aktivitas diatasnya.

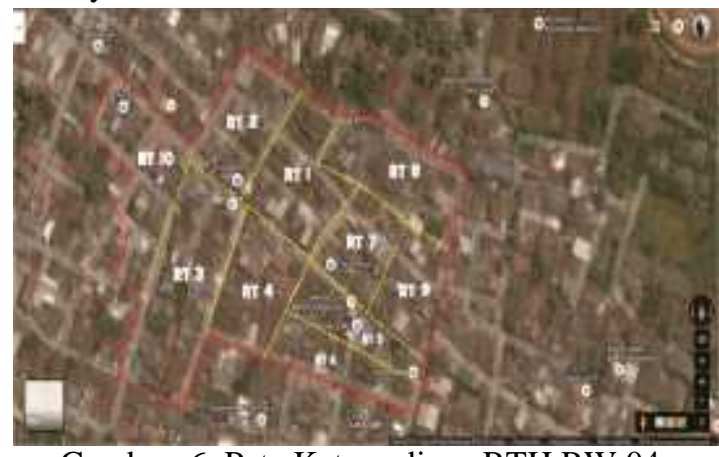

Gambar. 6. Peta Ketersediaan RTH RW.04

Kelurahan banta-bantaeng

Sumber : Google Earth 2017 
e. RW. 05

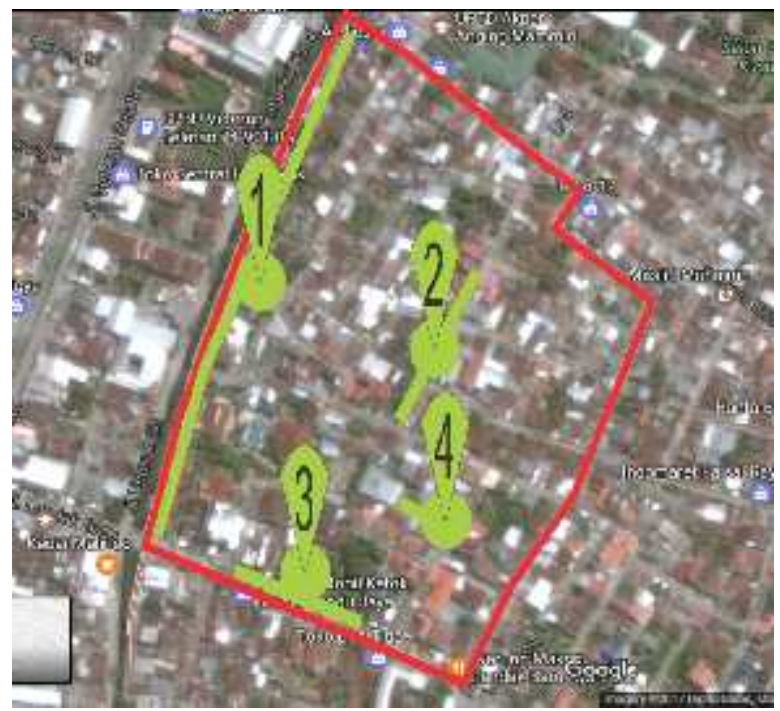

Gambar. 7 Ketersediaan dan penyebaran RTH RW 05 Kelurahan Banta-bantaeng

Sumber : Google Erath 2017

Tabel 6. jumlah ketersedian RTH publik pada RW.05

\begin{tabular}{|c|c|c|c|}
\hline No & $\begin{array}{c}\text { Titik } \\
\text { RTH } \\
\text { di } \\
\text { RW. } \\
05\end{array}$ & $\begin{array}{l}\text { Luas } \\
\text { RTH di } \\
\text { RW. } 05\end{array}$ & $\begin{array}{c}\text { Jumlah ketersedian RTH } \\
\text { publik di RW. } 05\end{array}$ \\
\hline 1 & $\begin{array}{l}\text { Titik } \\
.01\end{array}$ & $346.5 \mathrm{~m} 2$ & \multirow{2}{*}{$\begin{array}{l}\mathrm{RTH} \\
\frac{\text { jumlah Iuas KIH }}{\text { Iuas wilayah KW }} \times 100 \%\end{array}$} \\
\hline 2 & $\begin{array}{l}\text { Titik } \\
.02\end{array}$ & $20 \mathrm{~m} 2$ & \\
\hline 3 & $\begin{array}{l}\text { Titik } \\
.03\end{array}$ & $60 \mathrm{~m} 2$ & \multirow{2}{*}{$\begin{array}{c}= \\
\frac{4 b 4 \cdot 4}{45 . / 18 \mathrm{~m} 2} \times 100 \%=5 \%\end{array}$} \\
\hline 4 & $\begin{array}{l}\text { Titik } \\
.04\end{array}$ & $28 \mathrm{~m} 2$ & \\
\hline
\end{tabular}

f. RW. 06

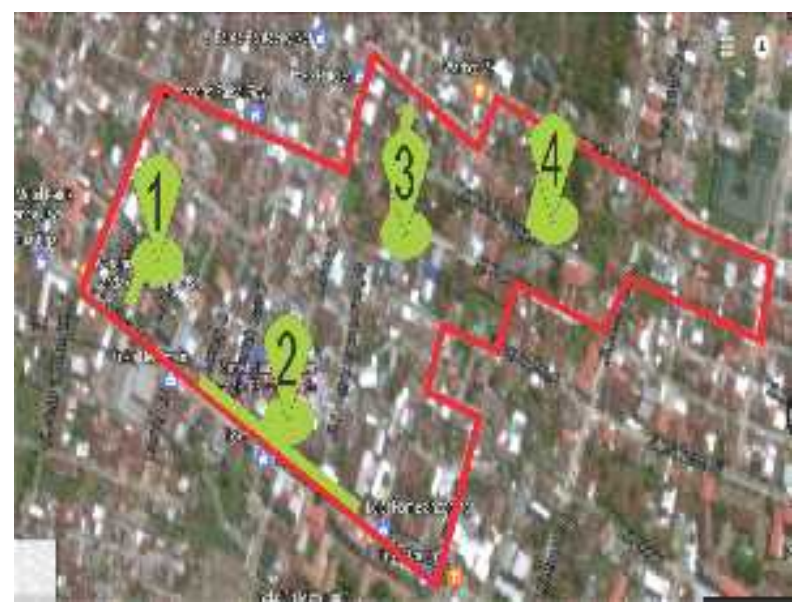

Gambar. 8. Ketersediaan dan penyebaran RTH RW 06 Kelurahan Banta-bantaeng Sumber : Google Erath 2017
Daerah penelitian ruang terbuka hijau pada lokasi RW 06 kelurahan Banta-bantaeng kecamatan Rapoccini, kota Makassar didapatkan data luas wilayah RW. $06210.05 \mathrm{~m} 2$ dan empat titik ruang terbuka hijau publik yang tersebar adapun data luasan ketersediaan ruang terbuka hijau publik RW. 06 kelurahan Banta-bantaeng sebagai berikut.

Tabel 7 Jumlah ketersedian RTH publik pada RW. 06 Kelurahan Banta-bantaeng

\begin{tabular}{|c|c|c|c|}
\hline No & $\begin{array}{c}\text { Titik } \\
\text { RTH } \\
\text { di } \\
\text { RW. } \\
06\end{array}$ & $\begin{array}{c}\text { Luas } \\
\text { RTH } \\
\text { di } \\
\text { RW. } \\
06\end{array}$ & $\begin{array}{c}\text { Jumlah ketersedian RTH publik } \\
\text { di RW. } 06\end{array}$ \\
\hline 1 & $\begin{array}{l}\text { Titik } \\
.01\end{array}$ & $\begin{array}{l}31.2 \\
\mathrm{~m} 2\end{array}$ & \multirow{2}{*}{$\begin{array}{l}\text { RTH } \\
\frac{\text { jualah Iuas KIH }}{\text { Iuas wilayah KW }} \times 100 \%\end{array}$} \\
\hline 2 & $\begin{array}{l}\text { Titik } \\
.02\end{array}$ & $\begin{array}{l}68 \\
\mathrm{~m} 2\end{array}$ & \\
\hline 3 & $\begin{array}{l}\text { Titik } \\
.03\end{array}$ & $\begin{array}{l}11 \\
\mathrm{~m} 2\end{array}$ & \multirow{2}{*}{$\begin{array}{l}= \\
\frac{19 L .7}{0.062 s \mathrm{mz}} \times 100 \%=1 \%\end{array}$} \\
\hline 4 & $\begin{array}{l}\text { Titik } \\
.04\end{array}$ & $\begin{array}{l}82.5 \\
\mathrm{~m} 2\end{array}$ & \\
\hline
\end{tabular}

2.2.4 Optimalisasi Penyediaan dan Distribusi RTH Optimalisasi distribusi RTH di Kelurahan Bantabantaeng dilakukan dengan menganalisis lokasilokasi/lahan-lahan yang ada untuk menyediakan dan mendistribusikan RTH sesuai perhitungan kebutuhan RTH yang ideal.

Tabel 8. Ketersediaan dan penyebaran RTH berdasarkan Luas Wilayah tiap RW di Kelurahan Banta-bantaeng Tahun 2017

\begin{tabular}{|c|c|c|c|c|c|}
\hline \multirow{2}{*}{ RW } & \multirow{2}{*}{$\begin{array}{c}\text { Luas } \\
\text { Wilayah } \\
\left(\mathbf{m}^{2}\right)\end{array}$} & \multirow{2}{*}{$\begin{array}{l}\text { Ratio } \\
\text { Luas } \\
\text { RTH }\end{array}$} & \multirow{2}{*}{$\begin{array}{l}\text { Luas } \\
\text { RTH } \\
\text { (m2) }\end{array}$} & \multicolumn{2}{|c|}{$\begin{array}{c}\text { RTH yang } \\
\text { tersedia }\end{array}$} \\
\hline & & & & (m2) & $(\%)$ \\
\hline $\begin{array}{l}\text { RW } \\
01\end{array}$ & 604.432 & \multirow{8}{*}{$20 \%$} & $120.886,40$ & $10.944,6$ & 1,80 \\
\hline $\begin{array}{l}\text { RW } \\
02\end{array}$ & 210.052 & & $42.010,40$ & 1.429 & 0,68 \\
\hline $\begin{array}{l}\text { RW } \\
03\end{array}$ & 372.536 & & $74.507,20$ & 16.401 & 4,40 \\
\hline $\begin{array}{l}\text { RW } \\
04\end{array}$ & 93.718 & & $18.743,60$ & - & 0,00 \\
\hline $\begin{array}{l}\text { RW } \\
05\end{array}$ & 121.397 & & $24.279,40$ & 454,4 & 0,37 \\
\hline $\begin{array}{l}\text { RW } \\
06\end{array}$ & 212.903 & & $42.580,60$ & 192,7 & 0,09 \\
\hline $\begin{array}{l}\text { RW } \\
07\end{array}$ & 205.754 & & $41.150,80$ & 31.115 & 15,12 \\
\hline $\begin{array}{l}\text { RW } \\
08\end{array}$ & 183.747 & & 36749,40 & - & 0,00 \\
\hline
\end{tabular}

Sumber : Hasil olah data 2017 


\section{KESIMPULAN}

Adapun kesimpulan dari penelitian ini yaitu :

a. Ketersediaan Ruang Terbuka Hijau pada kelurahan Banta-bantaeng

b. belum dan tidak memenuhi standar kebutuhan RTH. Dari 8 RW yang menjadi wilayah studi menunjukkan bahwa RTH yang ada tidak memenuhi kriteria baik dari sisi ekologis maupun dari sisi sosial budaya.

c. Ruang Terbuka yang tersedia hampir sebagian besar adalah milik pribadi masyarkat/instansi yang belum terkelola sebagaimana yang terdapat pada RW 01, 02, 03.

d. Masih ada 2 wilayah RW yang bahkan tidak memiliki RTH, yaitu RW 04 dan RW.08.

e. Penyebaran Ruang Terbuka Hijau di Kelurahan Banta-bantaeng belum terdistribusi secara merata. Hal ini karena ketersediaan RTH yang memang belum memenuhi standar.

f. Padatnya beberapa kawasan permukiman pada wilayah Kelurahan Banta-bantaeng juga mempengaruhi ketersediaan dan penyebaran RTH di wilayah tersebut.

g. Optimalisasi distribusi RTH di Kelurahan Banta-bantaeng dilakukan dengan menganalisis lokasi-lokasi/lahan-lahan yang ada untuk menyediakan dan mendistribusikan RTH sesuai perhitungan kebutuhan RTH yang ideal.

Berdasarkan kesimpulan yang telah dirumuskan sebelumnya dan berdasarkan hasil kajian dan analisis maka disarankan beberapa hal sebagai berikut :

a. Untuk menyediakan RTH yang sesuai dengan standar kebutuhan, pemerintah dapat melakukan pendataan ruang terbuka atau lahan-lahan yang tidak produktif untuk direncanakan sebagai RTH.

b. Pdan enyediaan dan penyebaran RTH di kelurahan Banta-bantaeng sedapat mungkin disesuaikan dengan standar kebutuhan dan karakteristik sosial masyarakat agar RTH yang tersedia dapat lebih fungsionil.

c. Perlu peran serta masyarakat dan pemerintah untuk mengaktifkan lahan-lahan yang belum terkelola sebagai Ruang Terbuka Hijau sementara.

d. Penelitian ini adalah suatu penelitian pendahuluan yang difokuskan pada analisis ketersedian dan penyebaran ruang terbuka pada kelurahan Banta-bantaeng Kecamatan Rappocini Kota Makassar, sehingga untuk melanjutkan penelitian ini dapat melakukan penelitian yang berkaitan dengan model penyediaan dan penataan ruang terbuka Hijau.

\section{DAFTAR PUSTAKA}

Amin, Samsuddin, dkk, 2011, Evaluasi Ketersediaan Ruang Terbuka Hijau di Kompleks Perumahan Bumi Permata Sudiang
Kota Makassar, Prosiding hasil Penelitian Fakultas Teknik Volume 5 : Desember 2011

Budihardjo, Eko, (ed), 2009, Arsitektur Indonesia dari Perspektif Budaya, Alumni, Bandung

De Chiara, Joseph dan Lee E. Koppelman, 2005, Standar Perencanaan Tapak, Erlangga, Jakarta

Darmawan, Edy, 2005, Ruang Publik Dalam Pengembangan Spasial Kota, Proceeding Seminar Nasional Peran Ruang Publik Dalam Pengembangan Sektor Properti dan Kota, Jurusan Arsitektur Fakultas Teknik Unipersitas Diponegoro, Semarang

Hakim, Rustam, 1991, Tahapan dan Proses Perancangan dalam Arsitektur Lansekap, Universitas Trisakti, Jakarta.

Purnomo, Agus B, 2009, Teknik Kuantitatif Untuk Arsitektur dan Perancangan Kota, Rajawali Press, Jakarta

Purwanto, Edi, 2005, Ruang Publik sebagai Setting Perkotaan, Proceeding Seminar Nasional Peran Ruang Publik Dalam Pengembangan Sektor Properti dan Kota, Jurusan Arsitektur Fakultas Teknik Unipersitas Diponegoro, Semarang

Siregar, Laksmi G., 2005, Penyediaan Ruang Publik yang Me"Manusiawi"kan Kehidupan Kot Proceeding Seminar Nasional Peran Ruang Publik Dalam Pengembangan Sektor Properti dan Kota, Jurusan Arsitektur Fakultas Teknik Unipersitas Diponegoro, Semarang.

Singarimbun, Masri dan Sofian Efendi, 1989, Metode Penelitian Survey, LP3ES, Jakarta

Sukawi, 2005, Proceeding Seminar Nasional Peran Ruang Publik Dalam Pengembangan Sektor Properti dan Kota, Jurusan Arsitektur Fakultas Teknik Unipersitas Diponegoro, Semarang Peran Taman Kota sebagai Ruang Publik di Perkotaan, Studi kasus Taman Menetri Supeno Semarang,

Yosita, Lucy, 2005, Ruang Publik di Lingkungan Perumahan Permukiman Sebuah Telaah Perbandingan antara Kondisi di Indonesia dengan Negara-Negara Maju, Proceeding Seminar Nasional Peran Ruang Publik Dalam Pengembangan Sektor Properti dan Kota, Jurusan Arsitektur Fakultas Teknik Unipersitas Diponegoro, Semarang 